\title{
Recapitulation of Neuropsychiatric Behavioral Features in Mice Using Acute Low-dose MK-801 Administration
}

\author{
Darine Froy N. Mabunga ${ }^{1}$, Donghyun Park ${ }^{1}$, Onjeon Ryu ${ }^{1}$, Schley T. Valencia ${ }^{1}$, \\ Keremkleroo Jym L. Adil ${ }^{1}$, Seonmin Kim ${ }^{1}$, Kyoung Ja Kwon ${ }^{1}$, Chan Young Shin ${ }^{1,2 *}$ and Se Jin Jeon ${ }^{1 *}$ \\ ${ }^{1}$ Department of Neuroscience, School of Medicine, Konkuk University, ${ }^{2}$ Department of Pharmacology, School of Medicine, \\ Konkuk University, Seoul 05029, Korea
}

\begin{abstract}
Despite some innate limitations, animal models are a potent investigative tool when used to model specific symptoms of a disorder. For example, MK-801, an N-methyl-D-aspartate receptor antagonist, is used as a pharmacological tool to induce symptoms found in some neuropsychiatric disorders. However, a close examination of literature suggests that the application window of MK-801 doses is relatively narrow between individual behavioral paradigms, necessitating careful characterization of the evoked behavioral aberrations and the doses used to induce them. Moreover, variation in behaviors depending on the animal strain, gender of the subject, and the timing of administration is observed, making it difficult to compare the behavioral characteristics reported in different studies. We aim to characterize the behavioral aberrations induced by different doses of MK-801 in CD-1 mice and create a ready reference for future studies. We used CD-1 mice to recapitulate behavioral impairments resulting from acute administration of MK-801. In $0.1 \mathrm{mg} \mathrm{kg}^{-1}$, we observed diminished spontaneous alteration during the Y-maze test, while $0.12 \mathrm{mg} \mathrm{kg}{ }^{-1}$ resulted in hyperlocomotion and social deficit. Mice treated with 0.2 and $0.3 \mathrm{mg} \mathrm{kg}^{-1}$ of MK-801 demonstrated a decreased self-grooming. Finally, all doses significantly impaired cliff avoidance behaviors suggesting increased impulsivity. These results affirm that MK-801 can effectively model various symptoms of different neuropsychiatric disorders in a dose-dependent manner. The observed sensitivity against spatial-memory impairment and impulsive behaviors at low concentration of MK-801 suggest that MK801 may modulate cognitive function and impulsivity in even lower concentration before it can modulate other behavioral domains.
\end{abstract}

Key words: MK-801, Behavioral domains, Neuropsychiatric disorders, Animal model

\section{INTRODUCTION}

Some neuropsychiatric disorders, like autism spectrum disorder and attention-deficit hyperactivity disorder, start to manifest early in life and continue to burden affected individuals with other mental comorbidities through adulthood [1]. The prevalence of these disorders is alarmingly increasing that it has consequently

Received October 23, 2019, Revised December 20, 2019,

Accepted December 23, 2019

* To whom correspondence should be addressed.

Chan Young Shin, TEL: 82-2-2030-7834, FAX: 82-2-2030-7899

e-mail: chanyshin@kku.ac.kr

Se Jin Jeon, TEL: 82-2-454-5630, FAX: 82-2-2030-7899

e-mail: sjinjeon@hanmail.net resulted to their substantial contribution to the disease burden worldwide [2]. Frustratingly, market-available treatments are lacking, and the discovery of novel therapeutics has not seen extensive progress in decades. This may be traced to the complex pathobiology of neuropsychiatric disorders and that ethical and practical challenges obviously do not permit the examination of a living human brain [3]. However, researchers are trying to bridge the gap between these identified limitations and desired substantial progress through thoroughly utilizing animal models.

Using animal models works on the assumption that underlying behavioral and molecular mechanisms are evolutionary conserved across species [4]. While this assumption may be valid in modeling a single sensory or motor function, it may be inadequate in translating the entire complexities of human behavior. Modeling
Copyright (c) Experimental Neurobiology 2019.

www.enjournal.org
This is an Open Access article distributed under the terms of the Creative Commons Attribution Non-Commercial License (http://creativecommons.org/licenses/by-nc/4.0) which permits unrestricted non-commercial use, distribution, and reproduction in any medium, provided the original work is properly cited. 
a single human symptom may be more appropriate than trying to amalgamate symptoms to replicate a rather complex disorder. Fernando and Robbins have consequently argued that modeling the symptoms of a disorder, rather than its entirety, boosts the model's specificity, validity, and utility [5]. One model that has strong face validity in terms of recapitulating key symptoms of various neuropsychiatric disorders is the MK-801 rodent model.

MK-801, or dizocilpine, a N-methyl-D-aspartate receptor (NMDAR) antagonist, was first used as a pharmacologic model of psychosis in rats in 1999 [6] and is still widely utilized as a model for symptoms observed in schizophrenia. MK-801 may not be able to model schizophrenia in its entirety but it can mimic particular cognitive deficits such as behavioral inflexibility [7], impaired spatial memory (reviewed in [8]), and social withdrawal [9]. However, the use of MK-801 as a pharmacological model should not be limited to the symptoms of schizophrenia, considering the complexity and the multiple overlapping domains of neuropsychiatric disorders in humans [10,11]. Considering this, researchers are afforded with avenues to try to recapitulate other psychiatric symptoms such as autism-related phenotypes on animals using MK-801 [12].

As a noncompetitive NMDAR antagonist, the stretch of MK801 's effect almost mirrors the span of the physiological response to glutamate transmission, affecting learning, memory, and motor activity and appears to be capable of eliciting a wide range of behavioral aberrations at varying doses. For example, a relatively higher dose of MK-801 (0.3 $\left.\mathrm{mg} \mathrm{kg}^{-1}\right)$ induced stereotypy [13] and ataxic movements $[14,15]$, while very low doses of MK-801, like $0.02 \mathrm{mg} \mathrm{kg}^{-1}$, demonstrated paradoxical effects on the behavior of C57Bl/6 mice. Behaviors like locomotion, rearing, and grooming were replaced with periods of immobility, suggesting behavioral inhibition [16]. Moreover, each mouse strain seemingly shows differential dose-response relationship for some of the MK-801-induced behaviors. For example, increase in locomotor activity was induced in CD-1 mice at $0.5 \mathrm{mg} \mathrm{kg}^{-1}$ of MK-801 in a two-hour observation of horizontal counts. BALB/C and C57Bl6/J mice, however, demonstrated increases in horizontal counts at $0.32 \mathrm{mg} \mathrm{kg}^{-1}$ [17]. "Popping, or irregular episodes of intense jumping behavior, was observed in the Balb/c mouse strain when administered with $0.56 \mathrm{mg} \mathrm{kg}^{-1}$ of MK-801 [18], while the same dose induced stereotypy in C57Bl/6 mice [13]. Several MK-801 studies utilizing inbred mouse strains have afforded a well-characterized account of the dosages and the behavioral phenotypes they induced. The same could not be said in outbred mouse strains, however. Thus, in this particular study, we chose to utilize CD-1 IGS (also known as Crl:CD1(ICR)) mice, one of the most commonly used outbred strains because it is robust, cheap to purchase, and can be easily reproduced, are robust $[19,20]$, with it being widely utilized in fields of cancer, toxicology, and pharmacology [20]. We examined a potential pre-clinical model for several types of MK-801-induced behavioral aberrations such as cognition impairment, hyperactivity, social impairment, and impulsivity present not only in neuropsychiatric disorders but also in neurodevelopmental disorders, using 4-week old male CD-1 mice.

\section{MATERIALS AND METHODS}

\section{Animals}

We purchased post-natal day 24 male CD-1 mice from Orient Bio (Seoul, Korea) and habituated them in the designated animal room for five days with automated systems for lights onand off-cycle (lights on - 24:00, lights off - 12:00) and a constant temperature $\left(23 \pm 2^{\circ} \mathrm{C}\right)$ and humidity $(50 \pm 10 \%)$. We provided them with food and water ad libitum. We performed all procedures in accordance with the Principles of Laboratory Animal Care (NIH publication No. 85-23, revised 1985), including animal treatments and maintenance and were implemented according to the Animal Care and Use Committee of Konkuk University, Korea (KU17143).

\section{Drugs}

We purchased (+)-MK-801 hydrogen maleate (MK-801 or Dizocilpine Cat No.77086-22-7) from Sigma-Aldrich (SigmaAldrich Korea, South Korea). We dissolved the MK-801 powder in $0.9 \% \mathrm{NaCl}$ solution at a volume of $10 \mathrm{ml} \mathrm{kg}^{-1}$ of body weight and administered to subject mice through intraperitoneal injection depending on their body weight (19 23g), while the vehicle group received the same volume of $0.9 \% \mathrm{NaCl}$ solution (Fig. 1).

\section{Behavioral tests}

\section{Open field test}

We measured the locomotor and exploratory activity of the mice treated with MK-801 through an open field test (OFT). The apparatus is made up of four boxes at sizes $40 \times 40 \times 30 \mathrm{~cm}$. We gently placed each mouse in the center of the arena and allowed it to freely explore the area for $30 \mathrm{~min}$. We designated the first five minutes as the habituation period and measured the total distance moved $(\mathrm{cm})$ and movement duration (s) for the remaining 25 minutes. We monitored all tests automatically using a computerized motion tracking apparatus and software equipped with a CCD camera using Ethovision software (version XT 14; Noldus Information Technology, Wageningen, the Netherlands).

\section{Y-maze}

Spontaneous alternation behavior measured in Y-maze requires 


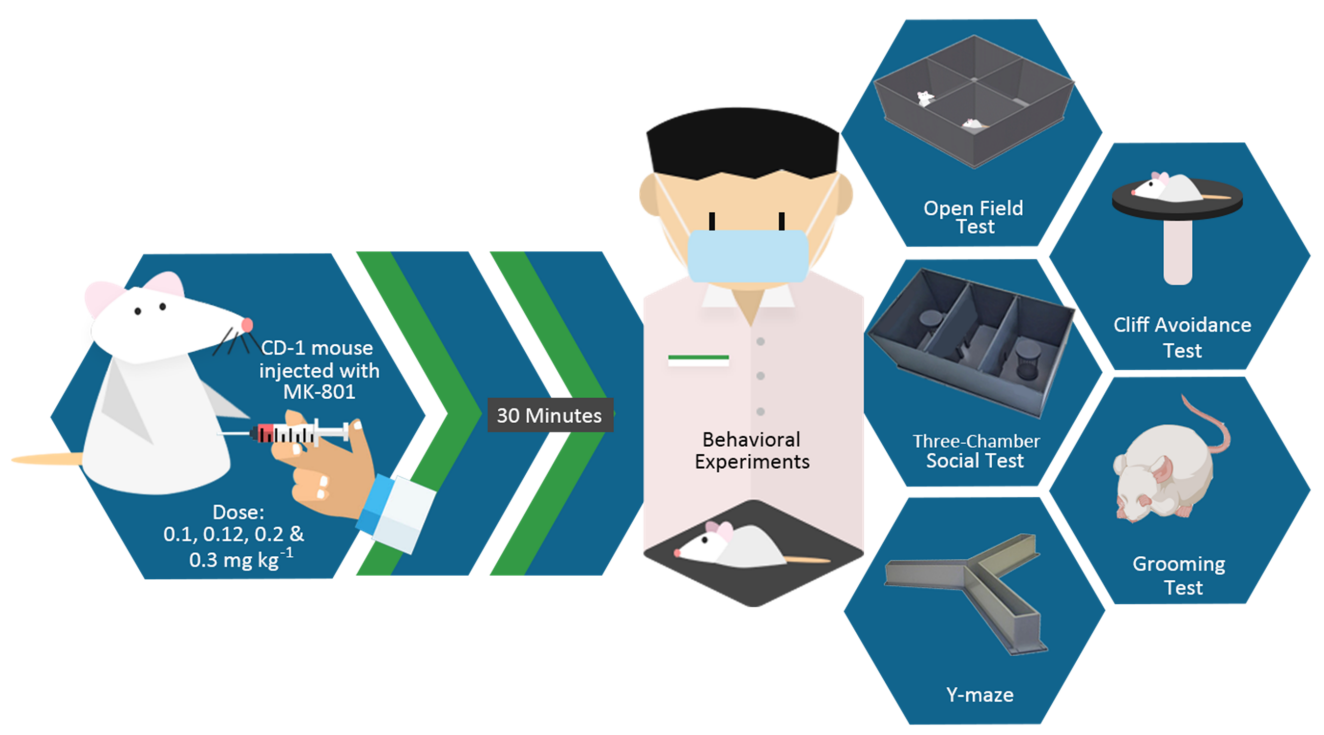

Fig. 1. Experimental scheme. Mice were allowed to habituate for five days in the designated animal facility. On the day of the experiment, MK-801 and saline were given 30 minutes prior to the test. attention [21] and working spatial memory. Normally, mice investigate a different arm of the maze rather than revisiting a previously explored one, indicative of sustained cognition [22]. We used a Y-shaped maze with three black, opaque, plastic arms at a $120^{\circ}$ angle from each other. Each arm measured $5.5 \mathrm{~cm}$ wide, $35 \mathrm{~cm}$ long, and $12.5 \mathrm{~cm}$ high. We first placed each mouse in one end of the $\mathrm{Y}$ maze, the start arm, facing the central intersection, and allowed to explore the maze for 8 minutes. We recorded an arm entry when four paws and tail of the mouse are within the arm zone and an actual alternation when there were consecutive entries into the three arms with a stepwise combination of the three different arms. We considered three successive entries to the different arms as a complete alternation. Total entries and percentage of spontaneous alternations calculated as (actual alternations/total entries -2$) \times 100$ were quantified and recorded.

\section{Three-chamber social assay}

Adapted from Crawley [23] and modified by Kim et al. [24], this assay examines the general sociability and preference for social novelty of a 4 -week old subject mice. We performed the test in an arena (70 $\mathrm{cm}$ wide, $40 \mathrm{~cm}$ long) with three communicating compartments, an environment novel to the mice. We used wire cages to encage the stranger mice. The dividing walls had rectangular openings providing access through the compartments. The chamber was cleaned before every trial. This test was divided into three phases. First was the habituation phase where the mouse was placed in the center compartment and was allowed to explore for 5 minutes. Immediately after the habituation, an encaged stranger mouse was added in a random side of the compartment and an empty wire cage on the other side, starting the social interaction phase. This measures the sociability of the subject mouse through its interaction with the novel mouse. Compartment preference index $(\% \mathrm{~S} / \mathrm{E})$ was defined as the ratio between the duration in stranger side (S) and empty side (E). After 10 minutes, we placed another stranger mouse in the empty compartment commencing the final phase, the social interaction phase. For another $10 \mathrm{~min}$ utes, we observed the subject mouse its preference between the familiar mouse $(\mathrm{F})$ and the novel mouse $(\mathrm{N})$ through compartment preference index ( $\%$ of $\mathrm{N} / \mathrm{F}$ ), the ratio between the duration spent in the novel and familiar side.

\section{Self-grooming test}

We performed the self-grooming test in the experimental mice as previously reported [25] with slight modification. Prior to the experiment, each mouse was placed in a polycarbonate cage $(42 \times 29 \times 19 \mathrm{~cm})$ without bedding and habituated for $10 \mathrm{~min}$. We recorded the total time spent with self-grooming for the succeeding $10 \mathrm{~min}$.

\section{Cliff avoidance test}

We measured cumulative jumping events (CJE) using a rounded platform (20 cm in diameter), supported by a plastic rod $(50 \mathrm{~cm}$ long), like a bar stool. Mice were gently placed on the platform and the latency to jump off the platform was recorded. Any mouse which fell from platforms was placed back on its home cage. The test went on for $20 \mathrm{~min}$. We calculated CJE as:

$$
\begin{aligned}
\%(\mathrm{CJE})= & \frac{(\text { number of total mice-the number of intact mice })}{\text { number of total mouse }} \\
& \times 100 \text { based on previously published papers }[26,27]
\end{aligned}
$$




\section{Statistical analysis}

All data are expressed as mean \pm standard error of the mean (SEM). We analyzed statistical significance using a one-way analysis of variance (ANOVA) followed by Tukey's multiple comparisons test, comparing the effects of each dose against the vehicle group; except that of the cumulative jumping events where we used Chi-square analysis. We performed all statistical analyses using GraphPad Prism Version 6.01 (California, USA) and set the significant $\mathrm{p}$-value at $<0.05$.

\section{RESULTS}

\section{Acute MK-801 administration results in changes in the locomotor activity of mice in the open field test}

We first examined the effects of the different doses of MK-801 on locomotion using open-field test, since locomotor hyperactivity is typically considered as one of the models for the positive symptoms of schizophrenia $[6,28]$ and is widely used in testing novel treatments for the disorder [29]. Consistent with published data $[16,30]$, we observed dose-dependent rise in locomotor activity $\left[\mathrm{F}_{(5,71)}=10.57, \mathrm{p}<0.0001\right]$ in mice administered with a single dose of MK-801, except in $0.1 \mathrm{mg} \mathrm{kg}^{-1}$ (Fig. 2). All the administered doses, however, elicited a significant increase in the total duration of movement of the mice (data not shown).

A.

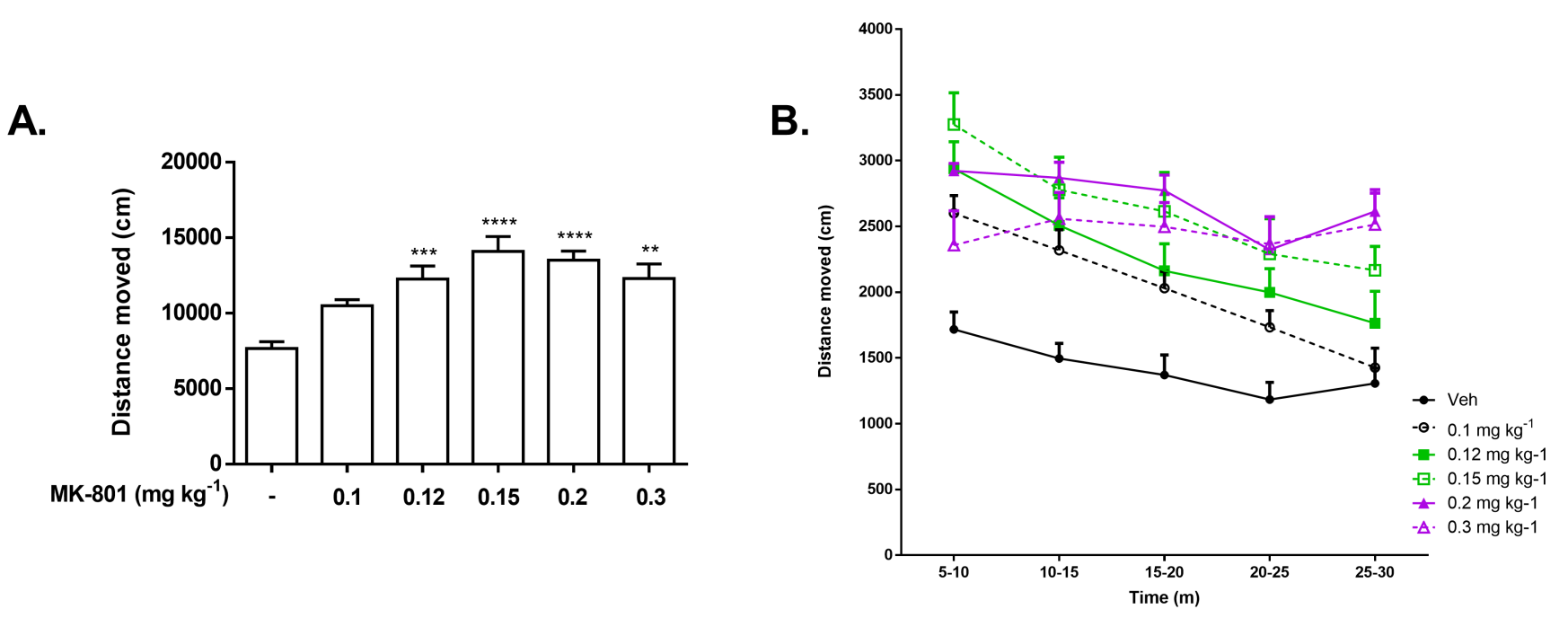

\section{Acute MK-801 administration alters spontaneous} alternation and total arm entries of mice in Y-maze

We observed perturbed spatial working memory as shown by a significant decline in the spontaneous alternation of CD-1 mice administered with $0.1 \mathrm{mg} \mathrm{kg}^{-1}$ of MK-801 during Y-maze, without necessarily affecting their total arm entries to a significant level. Acute administration of MK-801 induced impairment in spontaneous alternation $\left[\mathrm{F}_{(5,84)}=10.74, \mathrm{p}<.0001\right]$ in all doses. Except for 0.1 $\mathrm{mg} \mathrm{kg}^{-1}$, the other doses resulted to an increase in the total number of entries $\left[\mathrm{F}_{(5,84)}=7.981, \mathrm{p}<0.0001\right]$ (Fig. 3).

\section{Acute MK-801 administration disrupts social behaviors of mice in the three-chamber social assay}

Another test paradigm we performed in this study was the threechamber social assay. We observed a decrease in social interaction, but not in social preference, in mice treated with 0.12 and $0.15 \mathrm{mg}$ $\mathrm{kg}^{-1}$ of MK-801. This observation agrees with the reported social dysfunction found in mice administered with MK-801 in other studies [31-33]. As is shown in Fig. 4, MK-801 exerted a reducing effect in the duration of stay in the stranger side and increase in the empty side $\left[\mathrm{F}_{(8,276)}=3.546, \mathrm{p}=0.0006\right]$ in the subject mice. This observation was mirrored in groups administered with MK-801 at doses 0.12 and $0.15 \mathrm{mg} \mathrm{kg}^{-1}$ as they showed a significant decrease in sociability index $\left[\mathrm{F}_{(4,92)}=3.062, \mathrm{p}=0.0204\right]$ (Fig. 4B). Although there were no significant differences in the social preference test (Fig. 4C D), a noticeable dose-dependent trend is observed which mirrors that of the result seen in the social interaction test.

Fig. 2. Effects of MK-801 administration on locomotor activity of mice in the open field test. Subject mice were administered with either MK-801 (0.1, $0.12,0.15,0.2$ and $0.3 \mathrm{mg} \mathrm{kg}^{-1}$ ) or $0.9 \% \mathrm{NaCl}$ thirty minutes prior to the experiment. Open field test was then performed for 25 minutes, measuring the distance moved (Fig. 2A) and its progression in a five-minute time bin (Fig. 2B) as parameters. Data were analyzed using a one-way ANOVA test and are expressed as the mean \pm S.E.M ( $\mathrm{n}=10 \sim 15$ mice per group). ${ }^{*} \mathrm{p}<0.05,{ }^{* *} \mathrm{p}<0.01,{ }^{* * *} \mathrm{p}<0.001,{ }^{* * *} \mathrm{p}<0.0001$ vs. vehicle group as revealed by post hoc Tukey's multiple comparisons test. 
A.

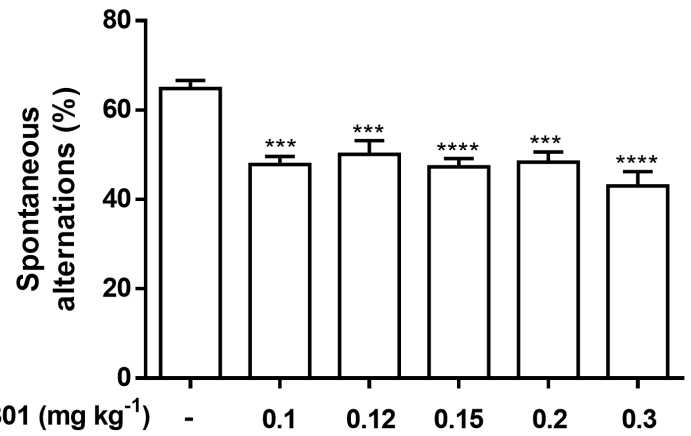

B.

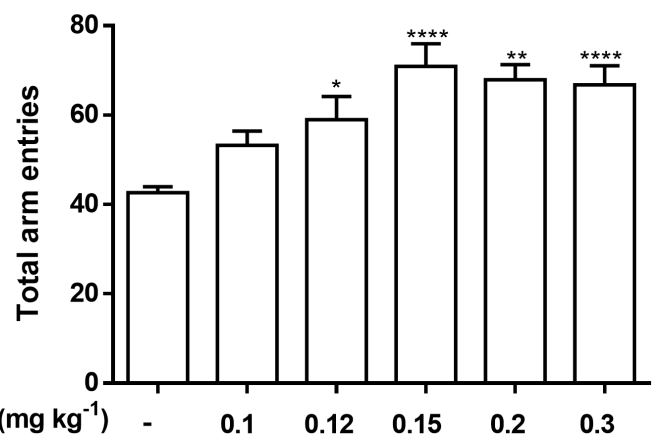

Fig. 3. Effects of MK-801 administration on spontaneous alternation and total arm entries of mice in Y-maze. Y-maze was performed on mice thirty minutes after they were administered with either MK-801 (0.1, 0.12, 0.15, 0.2 and $\left.0.3 \mathrm{mg} \mathrm{kg}^{-1}\right)$ or $0.9 \% \mathrm{NaCl}$. Parameters measured were the percentage of spontaneous alternations (Fig. 3A) and the total number of arm entries (Fig. 3B). All data are expressed as the mean \pm S.E.M ( $\mathrm{n}=10 \sim 20 \mathrm{mice}$ per group). ${ }^{* * *} \mathrm{p}<0.001,{ }^{* * *} \mathrm{p}<0.0001$ vs. vehicle group as revealed by post hoc Tukey's multiple comparisons test.

A.

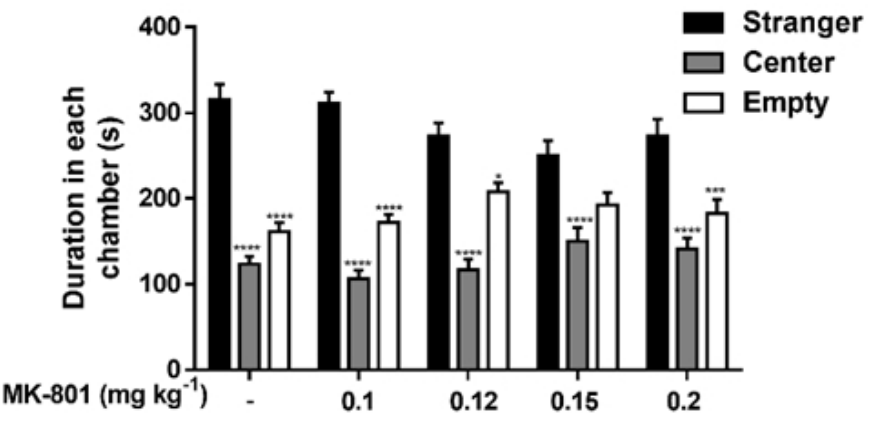

C.

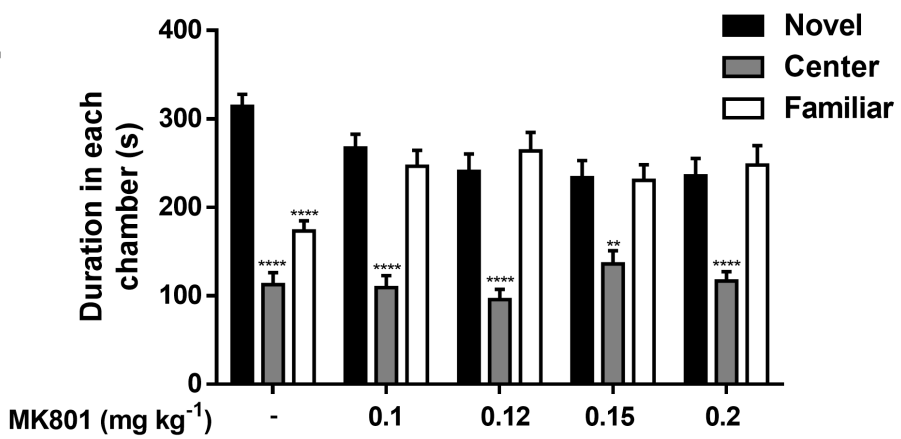

B.

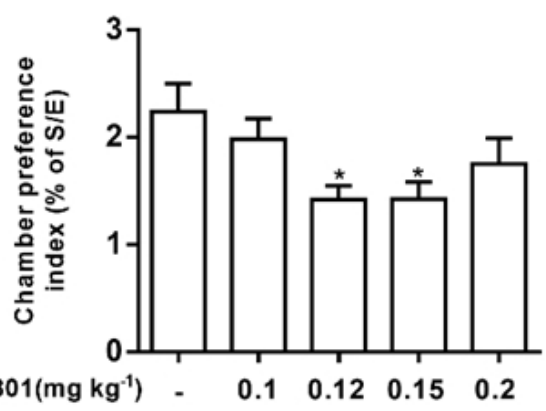

D.

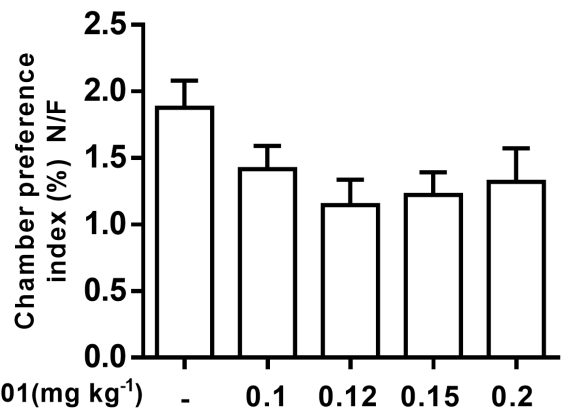

Fig. 4. Effects of MK-801 administration on social behaviors of mice in the three-chamber social assay. Subject mice were administered with either MK-801 $\left(0.1,0.12,0.15,0.2\right.$ and $\left.0.3 \mathrm{mg} \mathrm{kg}^{-1}\right)$ or $0.9 \% \mathrm{NaCl}$ thirty minutes prior to performing three-chamber social assay. Fig. $4 \mathrm{~A}$ shows the effects of MK-801 on the stay duration of mice in the stranger, center, and empty sides. The chamber preference index for the social interaction phase was then calculated as described in the Materials and Methods section and is shown in Fig. 4B. Figs. 4C and 3D demonstrate the effects of MK-801 on the social preference phase. All data are expressed as the mean \pm S.E.M ( $n=15 \sim 20$ mice per group). ${ }^{*} p<0.05,{ }^{* *} p<0.01,{ }^{* * *} p<0.001$, ${ }^{* * *} p<0.0001$ vs. vehicle group as revealed by post hoc Tukey's multiple comparisons test.

\section{Effects of acute MK-801 administration on self-grooming behavior of mice}

Fig. 5 shows the effects of MK-801 on self-grooming behavior of mice. Significant inhibitory-like effects on self-grooming were observed at the higher dose range of the compound, 0.2 and $0.3 \mathrm{mg}$ $\mathrm{kg}^{-1}\left[\mathrm{~F}_{(5,80)}=13.62, \mathrm{p}<0.0001\right]$. On the other hand, groups adminis- tered with 0.1 and $0.12 \mathrm{mg} \mathrm{kg}^{-1}$ of MK-801 demonstrated a slight increase in self-grooming behavior, though not at a significant level. 


\section{Acute MK-801 administration diminishes cliff avoidance reaction of mice in the cliff-avoidance test}

In our study, we chose the cliff avoidance test observing for the cumulative number of jumps as a measure of impulsivity [34, 35 ] as it allowed the acute administration of MK-801. All groups treated with MK-801 exhibited a significant impairment of their

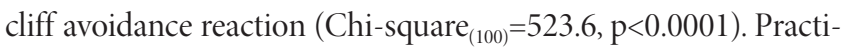
cally, $50 \%$ of MK-801-treated mice jumped down at an 8-min time point, except for those administered with 0.1 and $0.2 \mathrm{mg} \mathrm{kg}^{-1}$. In the jumping latency (s), 0.12 and $0.2 \mathrm{mg} \mathrm{kg}^{-1}$ showed a significant decrease in the latency time, while $0.3 \mathrm{mg} \mathrm{kg}^{-1}$ demonstrated the shortest (Fig. 6).

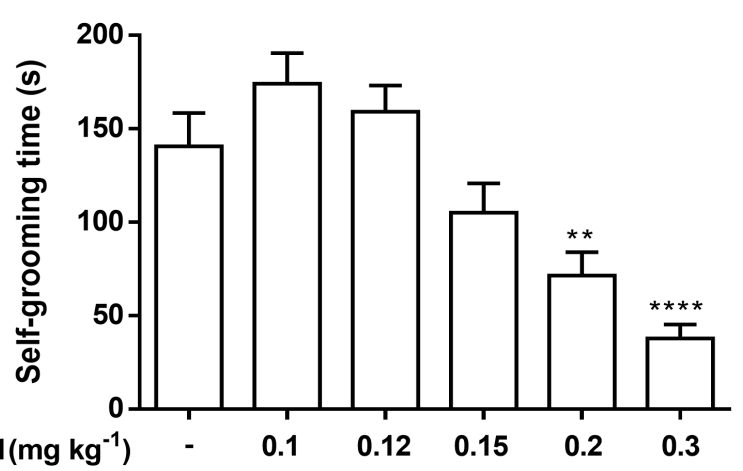

Fig. 5. Effects of MK-801 administration on the self-grooming behavior of mice. Subject mice were administered with either MK-801 (0.1, 0.12, $0.15,0.2$ and $0.3 \mathrm{mg} \mathrm{kg}^{-1}$ ) or $0.9 \% \mathrm{NaCl}$ thirty minutes prior to the observation of self-grooming behavior. The total time spent self-grooming was then measured and recorded. All data expressed as the mean \pm S.E.M ( $\mathrm{n}=14 \sim 15$ mice per group). ${ }^{*} \mathrm{p}<0.05,{ }^{* * *} \mathrm{p}<0.0001 \mathrm{vs}$. Vehicle group as revealed by post hoc Tukey's multiple comparisons test.

\section{DISCUSSION}

Earlier studies have implicated NMDAR blockade as the primary mechanism for the schizophrenia-like brain dysfunctions induced by phencyclidine (PCP) [36, 37]. Hence, NMDAR hypofunction hypothesis of schizophrenia has been postulated as either an alternative or a link to the dopamine hypothesis. Along with PCP, ketamine and MK-801 are widely used non-competitive NMDAR antagonists in modeling symptoms of schizophrenia in both humans and rodents. Also, using MK-801, Xi et al. [38] proposed that repeated injection of MK-801 at low doses $\left(<0.1 \mathrm{mg} \mathrm{kg}^{-1}\right)$ seemingly recapitulate the effects of NMDA hypofunction and that repeated administration of higher doses $\left(>0.3 \mathrm{mg} \mathrm{kg}^{-1}\right)$ produces results reminiscent to that of the positive symptoms observed in patients. Interestingly, memantine, another non-competitive NMDAR antagonist, is instead being considered as an adjunctive therapy for schizophrenia [39] (and reviewed in [40]). Studies pointed out that memantine regulates post-synaptic density protein transcripts differently compared to ketamine and MK-801 [41, 42]. In the current study, we demonstrated how MK-801 can be utilized not only to mimic behavioral symptoms limited to characterizing schizophrenia, but also of other neuropsychiatric disorders.

Here we demonstrated how systemic administration of MK801 at varying doses $\left(0.1,0.12,0.15,0.2\right.$, and $\left.0.3 \mathrm{mg} \mathrm{kg}^{-1}\right)$ exerts its effect on behaviors observed in different test paradigms using 4-week old CD-1 male mice. Interestingly, we observed a significant difference in the distance traveled between groups treated with $0.15 \mathrm{mg} \mathrm{kg}^{-1}$ and $0.3 \mathrm{mg} \mathrm{kg}^{-1}$ in 5- to 10 -min time point of the OFT session. The gap between the two doses narrowed during the next ten minutes and finally intersected before the 25-min time point. While the $0.15 \mathrm{mg} \mathrm{kg}^{-1}$ group showed decline in its traveled distance as time progressed, locomotion in $0.3 \mathrm{mg} \mathrm{kg}^{-1}$ was just
A.

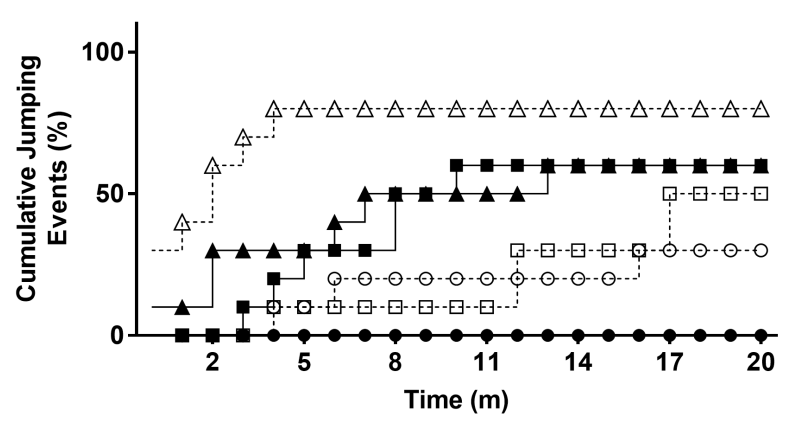

B.

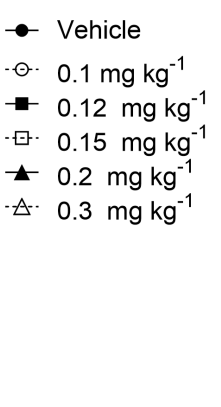

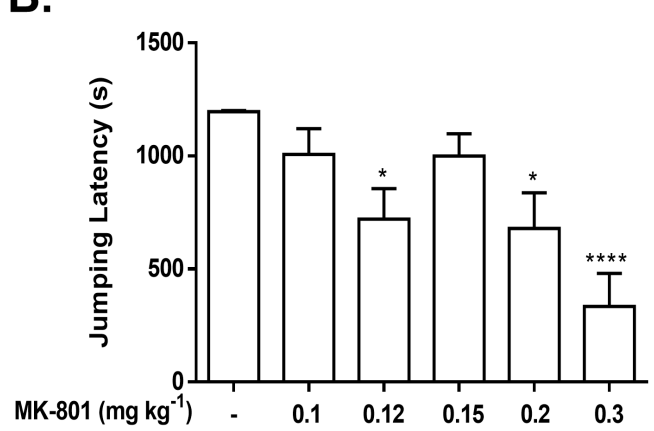

Fig. 6. Effects of MK-801 administration on cliff avoidance reaction of mice in the cliff-avoidance test. Cliff avoidance test was performed on mice thirty minutes after they were administered with either MK-801 $\left(0.1,0.12,0.15,0.2\right.$ and $\left.0.3 \mathrm{mg} \mathrm{kg}^{-1}\right)$ or $0.9 \% \mathrm{NaCl}$, with CJE in a 1-min time bin (Fig. $6 \mathrm{~A}$ ) and jumping latency (Fig. 6B) as parameters measured. All data are expressed as the mean \pm S.E.M $\left(\mathrm{n}=10\right.$ mice per group). ${ }^{*} \mathrm{p}<0.05,{ }^{* * *} \mathrm{p}<0.001$, ${ }^{* * * *} \mathrm{p}<0.0001$ vs. vehicle group as revealed by post hoc Tukey's multiple comparisons test and Chi-square analysis test. 
beginning to rise by the end of the 30-min observation period. The initially slower increase in the locomotion observed in $0.3 \mathrm{mg}$ $\mathrm{kg}^{-1}$ might be attributed to the reported stereotypy in high doses of MK-801 [13], though not measured in this study, or to the gradual degradation of the effects of MK-801 which was observed to peak at 40 60 min in the rat's brain ECF concentration after systemic injection [43]. We also observed ataxic-like movements at doses 0.5 and $1 \mathrm{mg} \mathrm{kg}^{-1}$ (data not shown). The apparent manifestation of stereotypy in $0.3 \mathrm{mg} \mathrm{kg}^{-1}$ group requires researchers to be more criti$\mathrm{cal}$ in analyzing locomotor behavior in subject mice. Stereotypy, though signifying another type of abnormal or repetitive behavior, may obscure other natural behaviors of the mice.

Also, NMDAR antagonists such as ketamine, PCP, and MK801 in various studies were used to further examining the role of NMDA in learning and memory. NMDARs are reported to preferentially regulate cortical GABA interneurons [44] and their blockade may result to the disinhibition of the medial prefrontal cortex, an important neural substrate aiding in the modulation of working memory in rodents [45], and subsequent increase in glutamate release [46] may possibly result to working memory deficit [47]. In our study, although doses higher than $0.1 \mathrm{mg} \mathrm{kg}^{-1}$ effectively impaired spontaneous alternation of the subject mice, they have also increased the total number of their arm entries, which may be imputed to the induced hyperlocomotion in these dosages. While a valid cognition impairer, the application window of MK-801 is relatively narrow [8] as sensorimotor side effects appear at slight increases of the dose, suggesting that a dose threshold of NMDAR antagonists must be maintained to produce memory deficits without necessarily affecting locomotion and sensorimotor processing $[48,49]$. While there are several studies which have identified doses of NMDAR antagonists that only result to memory deficits, they have not elucidated the mechanisms of such threshold. It might be possible that even low doses of NMDAR blockers, such as MK801 , might be enough to perturb the working memory based on the hypothesis that NMDAR antagonists preferentially affect the NMDARs on inhibitory neurons which causes a net disinhibition of principal cell activity controlling the firing of pyramidal neurons [50]. Interestingly, mice lacking NMDARs in fast-spiking parvalbumin interneurons demonstrated only selective working memory deficit [51] compared to the genetic deletion of NMDAR in a mixed population of GABAergic interneurons which is reported to have induced a wide range of aberrant behaviors, including deficits in cognition and PPI, novelty-induced hyperlocomotion, and anxiety-like behaviors [52]. Further studies will be required to confirm whether MK-801 also preferentially targets the NMDARs in the fast-spiking parvalbumin interneurons explaining the mentioned threshold. Indeed, the use of low dose
MK-801 as a model for cognitive dysfunction helps in preventing non-cognitive side effects, such as hyperlocomotion, from complicating result interpretation.

Most often, researchers interpret NMDAR antagonist-induced social behavior deficits as a model of negative symptoms of schizophrenia $[9,53,54]$, lending further support to the NMDA receptor hypofunction hypothesis of schizophrenia [55]. However, deficits in social behavior are predominantly non-specific and that NMDAR hypofunction-induced social dysfunctions are also consistent with autism-like phenotypes [56]. For example, Neuroligin- $1^{-1-}$ and Shank $2{ }^{-}$mice exhibited reduced NMDAR function, along with mild to marked social deficits and increased self-grooming $[57,58]$. NMDARs interact with signaling molecules, scaffolding proteins, and other receptors to mediate enduring changes in synaptic strength through downstream signaling pathways [59]. These components interacting with NMDARs must maintain a delicate balance among them to ensure a homeostatic functioning of the receptor, and that any upstaging of this equilibrium may result to NMDAR dysfunction [60]. For one, NMDA is implicated in the regulation of the mammalian target of rapamycin complex 1 (mTORC1), whose overactivity contributes significantly to social dysfunction and cognitive deficits in patients with tuberous sclerosis complex (TSC) [61]. NMDAR activation, through modulating intraneuronal concentration of arginine and controlling the phosphorylation state of extracellular signal regulating kinase $1 / 2$ (ERK1/2), may dampen mTORC1 activity [61]. Studies associating NMDAR hypofunction with autism allow the exploration of MK801 as a model for other autistic-like phenotypes. One study demonstrated autistic-like electrophysiological endophenotypes such as alterations in $\mathrm{P} 1$ and $\mathrm{N} 1$ latency, evoked gamma power, gamma inter-trial coherence, and gamma baseline, upon administration of MK-801 [12]. However, some of these symptoms are also shared by schizophrenia, suggesting that MK-801 instead models the overlapping neurophysiological characteristics between schizophrenia and ASD.

In this regard, we also measured the changes in self-grooming induced by MK-801. Interestingly, we observed a marked decline in the time spent by mice administered with higher doses of MK801 in self-grooming. This could be from the increasing locomotor activity of the experimental mice. It should be noted that these observations were recorded after a ten-minute habituation to the novel environment; thus, we did not observe the proposed stereotypy earlier which might have caused the initial slower increase in the locomotion of the $0.3 \mathrm{mg} \mathrm{kg}^{-1}$ group during OFT. Also, stereotypy reported in other MK-801 studies were broadly defined and typically involved head weaving, rotation, or ataxic behaviors [13], and not necessarily the observation of self-grooming behaviors. 
Although to a degree, glutamate is also implicated in the modulation of self-grooming [62]. Repeated subchronic exposure to PCP, for example, induced an increase in self-grooming in rats, but only disrupted the self-grooming behavior sequencing when the animals were under stress [63].

Finally, acute administration of MK-801 at select dosages influences impulsivity control in CD-1 mice. To our knowledge this is the first study demonstrating how MK-801 impacts impulsivity in mice. Interestingly, while groups given with $0.12,0.2$, and $0.3 \mathrm{mg}$ $\mathrm{kg}^{-1}$ MK-801 exhibited a significant decrease in jumping latency (s), the mice administered with $0.15 \mathrm{mg} \mathrm{kg}^{-1}$ did not. Impulsive behavior (CAR) is modulated by complex interplay of several neurotransmitter systems in several brain regions such as nucleus accumbens, amygdala, etc. It might be possible that different concentrations of MK-801 may have different effects on different neurotransmitters, which may affect the outcome of CAR. Future studies such as microdialysis examination of MK-801 effects on neurotransmitters may aid to find the answer of the seemingly complicated behavioral consequences.

In Long-Evans and Sprague-Dawley rats, MK-801 induced an increase in premature responding in 5-CSRT at 0.015 and 0.063 $\mathrm{mg} \mathrm{kg}^{-1}$, respectively $[58,59]$. While we examined whether acute administration of MK-801 influences impulsivity control in CD-1 mice. Reports have demonstrated that systemic injections of NMDAR antagonists, including MK-801, induce impulsive behavior in rodents determined through five-choice serial reaction time task (5-CSRT) [64, 65], implicating the neurotransmission of glutamate in impulsivity and making NMDARs a novel target to assuage impulsive symptoms [66]. However, while some studies attributed impulsive behavior to excess extracellular glutamate [46, 67], Murphy et al. [68] argued that resultant behavioral changes may be independent of this. They suggested that excessive glutamate after NMDAR antagonism in the infralimbic prefrontal cortex may activate GABAergic interneurons, which modulates the activity of projecting pyramidal cells, ultimately inhibiting output pyramidal neurons. Their study also demonstrated that $\mathrm{GABA}_{\mathrm{A}}$ receptor antagonism antagonized the effect of NMDAR blockade on impulsivity, highlighting the intricacy of the interaction of the glutamate-GABA systems in the prefrontal cortex.

Nevertheless, to fully characterize the effect of MK-801 on impulsivity in mice, other test paradigms measuring impulsive behavior must be employed, such as the above-mentioned 5-CSRT, stop-signal task, or go/no-go task. However, the timing and duration of drug administration must be carefully considered as these tests require training before the actual test.

Our study recapitulated well-characterized MK-801-induced behavioral aberrations such as hyperlocomotion, social behavior deficits, and cognitive dysfunction using CD-1 mice, in a dose-dependent manner (summarized in Supplementary Table 1). However, the observed variations of the elicited behavior from different doses require researchers to be critical in choosing the appropriate dose to model desired neuropsychiatric symptoms, considering that increased locomotor activity may confound the interpretation of some test paradigms. We also recommend that doses lower than what we used in this study should be investigated. For example, 0.1 $\mathrm{mg} \mathrm{kg}{ }^{-1}$ of MK-801 has significantly decreased spontaneous alternation of subject mice in Y-maze, without increasing arm entries. It is possible that lower doses such as $0.05 \mathrm{mg} \mathrm{kg}^{-1}$ may also produce the same impairment, as it has produced cognitive dysfunctions in other similar test paradigms (Supplementary Table 2). The same can also be said in cliff avoidance test. It is also important to note that short-term spatial memory and impulsivity control has shown most sensitivity to the lowest dose of MK-801 used in this study as shown by the perturbed spontaneous alternation in the Y-maze test and increased jumping in CAR test, implying that MK-801 affects the cognition and impulse control first before it modulates other behavior.

The test paradigms that we have performed in this study could be used in acutely modeling several symptoms not only of schizophrenia, but also that of autism. In addition to the two aforementioned disorders, one study examined the effects of multiple administration of MK-801 at $0.5 \mathrm{mg} \mathrm{kg}^{-1}$ to mice at postnatal day 1 and observed symptoms of hyperactivity and inattention and cell degeneration in hippocampus, frontal cortex, cerebellum, and parietal cortex, linking them to possible mechanisms of attentiondeficit hyperactive disorder (ADHD) [69]. In fact, there is a growing plethora of studies, in both humans and animals, implicating glutamatergic dysfunction in the disorder genesis of ADHD like the observation of genetic polymorphisms in NR2A and NR2B subunits of NMDAR in ADHD patients [70] or the demonstration of dysfunctional NR2B subunit and related reduction in synaptic transmission in spontaneous hypertensive rats [71], a prevailing animal model for ADHD. Indeed, the acute administration of MK-801 at relatively lower dose range to evaluate its transient behavioral effects on mice provides a rather straightforward way of modeling wider symptom spectra of various neuropsychiatric disorders, and that this model should not be limited in only recapitulating features of schizophrenia.

The straightforwardness in producing this animal model allows for ease in testing novel therapeutics against NMDA dysfunction or in evaluating the different regulatory roles of MK-801 in various neurotransmitter systems. However, how the resulting experimental data should be interpreted and related to a specific disorder requires careful judgment. Our current study has focused 
only on the acute effects of MK-801 administration in 4-week old male CD-1 mice, but manipulation of the timing and duration of administration or usage of female CD-1 should also be characterized in future studies using MK-801. The idea of treating MK-801 during prenatal to neonatal period, an evolution of NMDA hypofunction hypothesis, will also lend a neurodevelopmental element to the disease model [72].

\section{ACKNOWLEDGEMENTS}

This work was supported by the Bio \& Medical Technology Development Program of the National Research Foundation (NRF) funded by the Korean government (MSIT) (NRF2017M3A9G2077568), Business for Startup Growth and Technological Development (TIPS Program) funded by the Korean Ministry of SMEs and Startups (Grant No. S2525668) and the Korea Institute of Science and Technology (Grant No. 2E2922219-005).

\section{REFERENCES}

1. Stahlberg O, Soderstrom H, Rastam M, Gillberg C (2004) Bipolar disorder, schizophrenia, and other psychotic disorders in adults with childhood onset $\mathrm{AD} / \mathrm{HD}$ and/or autism spectrum disorders. J Neural Transm (Vienna) 111:891-902.

2. Whiteford HA, Degenhardt L, Rehm J, Baxter AJ, Ferrari AJ, Erskine HE, Charlson FJ, Norman RE, Flaxman AD, Johns N, Burstein R, Murray CJ, Vos T (2013) Global burden of disease attributable to mental and substance use disorders: findings from the Global Burden of Disease Study 2010. Lancet 382:1575-1586.

3. Mabunga DF, Gonzales EL, Kim JW, Kim KC, Shin CY (2015) Exploring the validity of valproic acid animal model of autism. Exp Neurobiol 24:285-300.

4. Razafsha M, Behforuzi H, Harati H, Wafai RA, Khaku A, Mondello S, Gold MS, Kobeissy FH (2013) An updated overview of animal models in neuropsychiatry. Neuroscience 240:204-218.

5. Fernando AB, Robbins TW (2011) Animal models of neuropsychiatric disorders. Annu Rev Clin Psychol 7:39-61.

6. Andiné P, Widermark N, Axelsson R, Nyberg G, Olofsson U, Mårtensson E, Sandberg M (1999) Characterization of MK801-induced behavior as a putative rat model of psychosis. J Pharmacol Exp Ther 290:1393-1408.

7. Svoboda J, Stankova A, Entlerova M, Stuchlik A (2015) Acute administration of MK-801 in an animal model of psychosis in rats interferes with cognitively demanding forms of behav- ioral flexibility on a rotating arena. Front Behav Neurosci 9:75.

8. van der Staay FJ, Rutten K, Erb C, Blokland A (2011) Effects of the cognition impairer MK-801 on learning and memory in mice and rats. Behav Brain Res 220:215-229.

9. Rung JP, Carlsson A, Rydén Markinhuhta K, Carlsson ML (2005) (+)-MK-801 induced social withdrawal in rats; a model for negative symptoms of schizophrenia. Prog Neuropsychopharmacol Biol Psychiatry 29:827-832.

10. Kas MJ, Fernandes C, Schalkwyk LC, Collier DA (2007) Genetics of behavioural domains across the neuropsychiatric spectrum; of mice and men. Mol Psychiatry 12:324-330.

11. Kalueff AV, Ren-Patterson RF, LaPorte JL, Murphy DL (2008) Domain interplay concept in animal models of neuropsychiatric disorders: a new strategy for high-throughput neurophenotyping research. Behav Brain Res 188:243-249.

12. Saunders JA, Gandal MJ, Roberts TP, Siegel SJ (2012) NMDA antagonist MK801 recreates auditory electrophysiology disruption present in autism and other neurodevelopmental disorders. Behav Brain Res 234:233-237.

13. Wu J, Zou H, Strong JA, Yu J, Zhou X, Xie Q, Zhao G, Jin M, Yu L (2005) Bimodal effects of MK-801 on locomotion and stereotypy in C57BL/6 mice. Psychopharmacology (Berl) 177:256-263.

14. Koyuncuoğlu H, Kara I, Günel MA, Nurten A, Yamantürk P (1998) N-methyl-D-aspartate antagonists, glutamate release inhibitors, 4-aminopyridine at neuromuscular transmission. Pharmacol Res 37:485-491.

15. Malomuzh AI, Mukhtarov MR, Urazaev AKh, Nikol'skii EE, Vyskochil F (2002) The effects of glutamate on spontaneous acetylcholine secretion processes in the rat neuromuscular synapse. Neurosci Behav Physiol 32:577-582.

16. Tang Y, Zou H, Strong JA, Cui Y, Xie Q, Zhao G, Jin M, Yu L (2006) Paradoxical effects of very low dose MK-801. Eur J Pharmacol 537:77-84.

17. Kalinichev M, Bate ST, Coggon SA, Jones DN (2008) Locomotor reactivity to a novel environment and sensitivity to MK-801 in five strains of mice. Behav Pharmacol 19:71-75.

18. Deutsch SI, Rosse RB, Paul SM, Riggs RL, Mastropaolo J (1997) Inbred mouse strains differ in sensitivity to "popping" behavior elicited by MK-801. Pharmacol Biochem Behav 57:315-317.

19. Cui S, Chesson C, Hope R (1993) Genetic variation within and between strains of outbred Swiss mice. Lab Anim 27:116123.

20. Kim JE, Nam JH, Cho JY, Kim KS, Hwang DY (2017) Annual tendency of research papers used ICR mice as experimental animals in biomedical research fields. Lab Anim Res 33:171- 
178

21. Katz RJ, Schmaltz K (1980) Dopaminergic involvement in attention. A novel animal model. Prog Neuropsychopharmacol 4:585-590.

22. Jackson LL (1943) VTE on an elevated T-maze. J Comp Psychol 36:99-107.

23. Crawley JN (2007) Mouse behavioral assays relevant to the symptoms of autism. Brain Pathol 17:448-459.

24. Kim KC, Kim P, Go HS, Choi CS, Yang SI, Cheong JH, Shin CY, Ko KH (2011) The critical period of valproate exposure to induce autistic symptoms in Sprague-Dawley rats. Toxicol Lett 201:137-142.

25. Kim JW, Seung H, Kwon KJ, Ko MJ, Lee EJ, Oh HA, Choi CS, Kim KC, Gonzales EL, You JS, Choi DH, Lee J, Han SH, Yang SM, Cheong JH, Shin CY, Bahn GH (2014) Subchronic treatment of donepezil rescues impaired social, hyperactive, and stereotypic behavior in valproic acid-induced animal model of autism. PLoS One 9:e104927.

26. Toriumi K, Tanaka J, Mamiya T, Alkam T, Kim HC, Nitta A, Nabeshima T (2018) Shati/Nat81 knockout mice show behavioral deficits ameliorated by atomoxetine and methylphenidate. Behav Brain Res 339:207-214.

27. Yamashita M, Sakakibara Y, Hall FS, Numachi Y, Yoshida S, Kobayashi H, Uchiumi O, Uhl GR, Kasahara Y, Sora I (2013) Impaired cliff avoidance reaction in dopamine transporter knockout mice. Psychopharmacology (Berl) 227:741-749.

28. Carlsson M, Carlsson A (1990) Interactions between glutamatergic and monoaminergic systems within the basal ganglia--implications for schizophrenia and Parkinson's disease. Trends Neurosci 13:272-276.

29. Okuyama S, Fukata T, Nishigawa Y, Amakura Y, Yoshimura M, Yoshida T, Nakajima M, Furukawa Y (2013) Citrus flavonoid improves MK-801-induced locomotive hyperactivity: possible relevance to schizophrenia. J Funct Foods 5:2002-2006.

30. Brosnan-Watters G, Wozniak DF, Nardi A, Olney JW (1996) Acute behavioral effects of MK-801 in the mouse. Pharmacol Biochem Behav 53:701-711.

31. Moy SS, Nonneman RJ, Shafer GO, Nikolova VD, Riddick NV, Agster KL, Baker LK, Knapp DJ (2013) Disruption of social approach by MK-801, amphetamine, and fluoxetine in adolescent C57BL/6J mice. Neurotoxicol Teratol 36:36-46.

32. Hanks AN, Dlugolenski K, Hughes ZA, Seymour PA, Majchrzak MJ (2013) Pharmacological disruption of mouse social approach behavior: relevance to negative symptoms of schizophrenia. Behav Brain Res 252:405-414.

33. Zou H, Zhang C, Xie Q, Zhang M, Shi J, Jin M, Yu L (2008) Low dose MK-801 reduces social investigation in mice. Phar- macol Biochem Behav 90:753-757.

34. Matsuoka Y, Furuyashiki T, Yamada K, Nagai T, Bito H, Tanaka Y, Kitaoka S, Ushikubi F, Nabeshima T, Narumiya S (2005) Prostaglandin E receptor EP1 controls impulsive behavior under stress. Proc Natl Acad Sci U S A 102:16066-16071.

35. Kumakura K, Nomura H, Toyoda T, Hashikawa K, Noguchi T, Takeda K, Ichijo H, Tsunoda M, Funatsu T, Ikegami D, Narita M, Suzuki T, Matsuki N (2010) Hyperactivity in novel environment with increased dopamine and impaired novelty preference in apoptosis signal-regulating kinase 1 (ASK1)deficient mice. Neurosci Res 66:313-320.

36. Lodge D, Anis NA (1982) Effects of phencyclidine on excitatory amino acid activation of spinal interneurones in the cat. Eur J Pharmacol 77:203-204.

37. Martin D, Lodge D (1988) Phencyclidine receptors and Nmethyl-D-aspartate antagonism: electrophysiologic data correlates with known behaviours. Pharmacol Biochem Behav 31:279-86

38. Xi D, Zhang W, Wang HX, Stradtman GG, Gao WJ (2009) Dizocilpine (MK-801) induces distinct changes of N-methyl$\mathrm{D}$-aspartic acid receptor subunits in parvalbumin-containing interneurons in young adult rat prefrontal cortex. Int J Neuropsychopharmacol 12:1395-1408.

39. Uribe E, Sánchez-Mendoza E, Nieves N, Merchor G (2016) Neonatal administration of memantine enhances social cognition in adult rats subjected to early maternal deprivation. Exp Neurobiol 25:328-332.

40. Di Iorio G, Baroni G, Lorusso M, Montemitro C, Spano MC, di Giannantonio M (2017) Efficacy of memantine in schizophrenic patients: a systematic review. J Amino Acids 2017:7021071.

41. de Bartolomeis A, Sarappa C, Buonaguro EF, Marmo F, Eramo A, Tomasetti C, Iasevoli F (2013) Different effects of the NMDA receptor antagonists ketamine, MK-801, and memantine on postsynaptic density transcripts and their topography: role of Homer signaling, and implications for novel antipsychotic and pro-cognitive targets in psychosis. Prog Neuropsychopharmacol Biol Psychiatry 46:1-12.

42. Uribe E, Landaeta J, Wix R, Eblen A (2013) Memantine reverses social withdrawal induced by ketamine in rats. Exp Neurobiol 22:18-22.

43. Wegener N, Nagel J, Gross R, Chambon C, Greco S, Pietraszek M, Gravius A, Danysz W (2011) Evaluation of brain pharmacokinetics of $(+) \mathrm{MK}-801$ in relation to behaviour. Neurosci Lett 503:68-72.

44. Homayoun H, Moghaddam B (2007) NMDA receptor hypofunction produces opposite effects on prefrontal cortex inter- 
neurons and pyramidal neurons. J Neurosci 27:11496-11500.

45. Perlstein WM, Carter CS, Noll DC, Cohen JD (2001) Relation of prefrontal cortex dysfunction to working memory and symptoms in schizophrenia. Am J Psychiatry 158:1105-1113.

46. Moghaddam B, Adams B, Verma A, Daly D (1997) Activation of glutamatergic neurotransmission by ketamine: a novel step in the pathway from NMDA receptor blockade to dopaminergic and cognitive disruptions associated with the prefrontal cortex. J Neurosci 17:2921-2927.

47. Suryavanshi PS, Ugale RR, Yilmazer-Hanke D, Stairs DJ, Dravid SM (2014) GluN2C/GluN2D subunit-selective NMDA receptor potentiator CIQ reverses MK-801-induced impairment in prepulse inhibition and working memory in Y-maze test in mice. Br J Pharmacol 171:799-809.

48. Carey RJ, Dai H, Gui J (1998) Effects of dizocilpine (MK-801) on motor activity and memory. Psychopharmacology (Berl) 137:241-246.

49. Liu W, Wang D, Hong W, Yu Y, Tang J, Wang J, Liu F, Xu X, Tan L, Chen X (2017) Psychotomimetic effects of different doses of MK-801 and the underlying mechanisms in a selective memory impairment model. Behav Brain Res 320:517-525.

50. Bygrave AM, Masiulis S, Nicholson E, Berkemann M, Barkus C, Sprengel R, Harrison PJ, Kullmann DM, Bannerman DM, Kätzel D (2016) Knockout of NMDA-receptors from parvalbumin interneurons sensitizes to schizophrenia-related deficits induced by MK-801. Transl Psychiatry 6:e778.

51. Carlén M, Meletis K, Siegle JH, Cardin JA, Futai K, VierlingClaassen D, Rühlmann C, Jones SR, Deisseroth K, Sheng M, Moore CI, Tsai LH (2012) A critical role for NMDA receptors in parvalbumin interneurons for gamma rhythm induction and behavior. Mol Psychiatry 17:537-548.

52. Belforte JE, Zsiros V, Sklar ER, Jiang Z, Yu G, Li Y, Quinlan EM, Nakazawa K (2010) Postnatal NMDA receptor ablation in corticolimbic interneurons confers schizophrenia-like phenotypes. Nat Neurosci 13:76-83.

53. Neill JC, Barnes S, Cook S, Grayson B, Idris NF, McLean SL, Snigdha S, Rajagopal L, Harte MK (2010) Animal models of cognitive dysfunction and negative symptoms of schizophrenia: focus on NMDA receptor antagonism. Pharmacol Ther 128:419-432.

54. Tsai G, Coyle JT (2002) Glutamatergic mechanisms in schizophrenia. Annu Rev Pharmacol Toxicol 42:165-179.

55. Coyle JT (2006) Glutamate and schizophrenia: beyond the dopamine hypothesis. Cell Mol Neurobiol 26:365-384.

56. Peñagarikano O (2015) New therapeutic options for autism spectrum disorder: experimental evidences. Exp Neurobiol 24:301-311.
57. Blundell J, Blaiss CA, Etherton MR, Espinosa F, Tabuchi K, Walz C, Bolliger MF, Südhof TC, Powell CM (2010) Neuroligin-1 deletion results in impaired spatial memory and increased repetitive behavior. J Neurosci 30:2115-2129.

58. Won H, Lee HR, Gee HY, Mah W, Kim JI, Lee J, Ha S, Chung C, Jung ES, Cho YS, Park SG, Lee JS, Lee K, Kim D, Bae YC, Kaang BK, Lee MG, Kim E (2012) Autistic-like social behaviour in Shank2-mutant mice improved by restoring NMDA receptor function. Nature 486:261-265.

59. Husi H, Ward MA, Choudhary JS, Blackstock WP, Grant SG (2000) Proteomic analysis of NMDA receptor-adhesion protein signaling complexes. Nat Neurosci 3:661-669.

60. Lee EJ, Choi SY, Kim E (2015) NMDA receptor dysfunction in autism spectrum disorders. Curr Opin Pharmacol 20:8-13.

61. Burket JA, Benson AD, Tang AH, Deutsch SI (2015) NMDA receptor activation regulates sociability by its effect on $\mathrm{mTOR}$ signaling activity. Prog Neuropsychopharmacol Biol Psychiatry 60:60-65.

62. Goodman WK, Grice DE, Lapidus KA, Coffey BJ (2014) Obsessive-compulsive disorder. Psychiatr Clin North Am 37:257-267.

63. Audet MC, Goulet S, Doré FY (2006) Repeated subchronic exposure to phencyclidine elicits excessive atypical grooming in rats. Behav Brain Res 167:103-110.

64. Paine TA, Tomasiewicz HC, Zhang K, Carlezon WA Jr (2007) Sensitivity of the five-choice serial reaction time task to the effects of various psychotropic drugs in Sprague-Dawley rats. Biol Psychiatry 62:687-693.

65. Higgins GA, Ballard TM, Huwyler J, Kemp JA, Gill R (2003) Evaluation of the NR2B-selective NMDA receptor antagonist Ro 63-1908 on rodent behaviour: evidence for an involvement of NR2B NMDA receptors in response inhibition. Neuropharmacology 44:324-341.

66. Pattij T, Vanderschuren LJ (2008) The neuropharmacology of impulsive behaviour. Trends Pharmacol Sci 29:192-199.

67. Ceglia I, Carli M, Baviera M, Renoldi G, Calcagno E, Invernizzi RW (2004) The 5-HT receptor antagonist M100,907 prevents extracellular glutamate rising in response to NMDA receptor blockade in the mPFC. J Neurochem 91:189-199.

68. Murphy ER, Fernando AB, Urcelay GP, Robinson ES, Mar AC, Theobald DE, Dalley JW, Robbins TW (2012) Impulsive behaviour induced by both NMDA receptor antagonism and GABAA receptor activation in rat ventromedial prefrontal cortex. Psychopharmacology (Berl) 219:401-410.

69. Fredriksson A,Archer T (2004) Neurobehavioural deficits associated with apoptotic neurodegeneration and vulnerability for ADHD. Neurotox Res 6:435-456. 
70. Turic D, Langley K, Mills S, Stephens M, Lawson D, Govan C, Williams N, Van Den Bree M, Craddock N, Kent L, Owen M, O'Donovan M, Thapar A (2004) Follow-up of genetic linkage findings on chromosome 16p13: evidence of association of $\mathrm{N}$-methyl-D aspartate glutamate receptor 2A gene polymorphism with ADHD. Mol Psychiatry 9:169-173.

71. Jensen V, Rinholm JE, Johansen TJ, Medin T, Storm-Mathisen J, Sagvolden T, Hvalby O, Bergersen LH (2009) N-methyl-D- aspartate receptor subunit dysfunction at hippocampal glutamatergic synapses in an animal model of attention-deficit/ hyperactivity disorder. Neuroscience 158:353-364.

72. Gilmour G, Dix S, Fellini L, Gastambide F, Plath N, Steckler T, Talpos J, Tricklebank M (2012) NMDA receptors, cognition and schizophrenia--testing the validity of the NMDA receptor hypofunction hypothesis. Neuropharmacology 62:14011412. 